\title{
Contribution of matrilysin (MMP-7) to the metastatic pathway of human colorectal cancers
}

\author{
Y Adachi, H Yamamoto, F Itoh, Y Hinoda, Y Okada, K Imai
}

\begin{abstract}
BackgroundlAim-Matrilysin is one of the matrix metalloproteinases that has a critical role in tumour invasion, and is often expressed in gastrointestinal cancers. The aim of this study was to examine the role of matrilysin in metastasis of human colorectal cancers.
\end{abstract}

Patients (Subjects)/Methods-The relation between matrilysin expression and Dukes's type was investigated immunohistochemically in 83 surgically resected colorectal cancers, including five with liver metastasis. Moreover, the effects of matrilysin on the in vivo invasive and metastatic potential of colon cancer cells transfected with matrilysin cDNA were examined after subcutaneous injection into SCID mice.

Results-In $46 \%$ of primary and all of metastatic liver tumours, over $10 \%$ of cancer cells were stained positively for matrilysin. The expression of matrilysin correlated significantly with the presence of nodal or distant metastases $(p<0.05)$. In addition, matrilysin transfectants formed invasive tumours and multiple liver metastases in SCID mice, without producing any significant difference in the subcutaneous tumour growth from mock transfectants. Casein zymography showed that the invading and metastasised tumours showed conspicuous matrilysin activity, which correlated with the number of metastatic lesions $(p<0.001)$.

Conclusions-Matrilysin showed a correlation with metastasis in a cohort of 83 colorectal cancer patients and marked metastatic potentiation in human colorectal cancer xenografts, indicating that it may play a critical role in the metastatic pathway of colorectal cancers.

(Gut 1999;45:252-258)

Keywords: matrix metalloproteinase; matrilysin; MMP-7; colorectal cancer; metastasis; transfection; human

Department of Pathology, School of Medicine, Keio

University, Tokyo 160 , Japan

Y Okada

Correspondence to: Dr F Itoh, First Department of Internal Medicine,

Sapporo Medical University, South-1, West-16, Chuo-ku, Sapporo 060, Japan.

Accepted for publication 9 February 1999 mature form and by a specific class of natural inhibitors, designated tissue inhibitor of metalloproteinases. ${ }^{45}$ MMPs are often active during tumour invasion, resulting in an excessive proteolytic degradation of the extracellular matrix.

Matrilysin (MMP-7) is a member of the MMP gene family and, after being activated, has a broad proteolytic activity against a variety of extracellular matrix substrates, including collagens, proteoglycans, elastin, laminin, fibronectin, and casein. ${ }^{6-8}$ Compared with other MMPs, matrilysin is distinguished by its low molecular mass $(28 \mathrm{kDa})$ and its lack of a C-terminal domain. Matrilysin was identified first in postpartum rat uterus, and has been detected in several normal tissues, such as endometrium, bronchial mucosa, monocytes, and mesangial cells. ${ }^{68}$ It is also produced by malignant tumour cells including prostate, gastric, head and neck, lung, hepatocellular, and colorectal carcinomas. ${ }^{9-12}$

We have previously reported that matrilysin mRNA is overexpressed in colorectal cancers. ${ }^{10}{ }^{11}$ It is noteworthy that only matrilysin and membrane type-1 MMP (MT1MMP) are produced by colorectal cancer cells themselves, whereas the other MMPs, such as MMP-1 (interstitial collagenase), MMP-2 (gelatinase A), MMP-9 (gelatinase B), and MMP-13 (stromelysin-3), are secreted by stromal cells. ${ }^{911}{ }^{13-21}$ Although matrilysin mRNA has been reported to increase with advancing colon cancer stage, ${ }^{22}{ }^{23}$ matrilysin protein has not been studied. Meanwhile, the unique structure of matrilysin and its localising pattern suggest that this enzyme may function in a manner distinct from other MMPs and may contribute directly to the invasive potential of colorectal cancers. We have shown that transfection of matrilysin cDNA caused colon cancer cells to be more invasive, as assessed by an in vitro invasion assay, ${ }^{24}$ and that the degree of invasion correlated with the levels of its secretion. ${ }^{25}$ In addition, downregulation of this proteinase by introduction of antisense matrilysin cDNA made these cells less invasive. ${ }^{24}$

In this study, to assess the clinical impact of matrilysin protein expression in colorectal tumours, an immunohistochemical examination was performed on 78 surgically resected specimens with colorectal cancer and on five with liver metastasis. In addition, the effect of matrilysin on in vivo invasive and metastatic ability was examined six weeks after subcutan-

Abbreviations used in this paper: $M M P$, matrix metalloproteinase; MT1-MMP, membrane type-1 matrix metalloproteinase; SDS, sodium dodecyl sulphate. 
eous transplantation with matrilysin transfected colon cancer cells into SCID mice. We report and discuss the effect of overexpression of matrilysin on colorectal cancer invasion and metastasis.

\section{Materials and methods}

TISSUES, CELLS, AND ANIMALS

All tissue samples with human colon cancer were obtained surgically. Each sample was fixed by the AMeX method ${ }^{26}$ and embedded in paraffin wax. A human colon cancer cell line CHC-Y1 was obtained from the Japanese Cancer Research Resources Bank (Osaka, Japan). Cells were maintained in RPMI 1640 containing $10 \%$ fetal bovine serum at $37^{\circ} \mathrm{C}$ in a humidified atmosphere of $5 \% \mathrm{CO}_{2}$ in air. Specific-pathogen-free female CB17/ICR Scid Jcl mice (six weeks old) were purchased from Clea Japan (Tokyo, Japan). They were maintained in a specific-pathogen-free environment, and their care and use were according to our university's guidelines.

\section{IMMUNOHISTOCHEMISTRY}

The sections were dewaxed in xylene and rehydrated in alcohol. The endogenous peroxidase activity was suppressed by a solution of hydrogen peroxide in methanol for 20 minutes. After being rinsed twice in phosphate buffered saline, the sections were incubated with non-immune rabbit serum for 20 minutes. The slides were treated with primary monoclonal antibody diluted in blocking solution for 18 hours at $4^{\circ} \mathrm{C}$. After being washed three times in phosphate buffered saline, the sections were treated with peroxidase conjugated rabbit antimouse immunoglobulin P-0260 (1:40 dilution; Dako, Glostrup, Denmark) for 30 minutes. The sections were developed in 3,3'diaminobenzidine $(0.6 \mathrm{mg} / \mathrm{ml})$ in $0.05 \mathrm{M}$ Tris/ $\mathrm{HCl}(\mathrm{pH} 7.5)$ containing $0.005 \%$ hydrogen peroxide at room temperature. The slides were counterstained in Mayer's haematoxylin and mounted.

Anti-matrilysin monoclonal antibody 1417B2 (mouse $\operatorname{IgG} 1)^{27}$ was generously provided by Fuji Chemical Industries (Toyama, Japan). This monoclonal antibody shows no cross reactivity with other MMPs, including MMP-1, MMP-2, MMP-3 (stromelysin-1), MMP-8 (neutrophil collagenase), and MMP-9. ${ }^{27}$ Monoclonal antibody AI-206 (mouse IgG1), an anti-idiotypic antibody, was used as negative control. The concentration of both primary antibodies used for immunostaining was $10 \mu \mathrm{g} / \mathrm{ml}$. Immunostaining signals were scored independently by two observers. The scores were calculated as the number of stained cells divided by the total number of carcinoma cells.

\section{CELL PROLIFERATION ASSAY}

Proliferation of tumour cells in vitro was measured using the colorimetric 3-(4,5dimethylthiazol)-2,5-diphenyltetrazolium bromide assay (Sigma, St Louis, Missouri, USA). Cells were harvested with $0.25 \%$ trypsin treatment, resuspended in medium alone, and plated in 96-well plastic tissue plates at $1 \times 10^{4}$ cells in $0.1 \mathrm{ml}$ per well. Five identical plates were set up for each cell line, and the cell number was determined after three different incubation periods $(0,12,24$, and 48 hours).

CELL MOTILITY ASSAY

An assay based on the ability of cells to clear colloidal gold particles, by phagocytosis, from the substratum as the cells move on it and form "phagokinetic tracks" was performed.$^{28}$ Briefly, 2000 cells were seeded on glass coverslides coated with bovine serum albumin and colloidal gold and were placed in $35 \mathrm{~mm}$ tissue culture dishes containing $2 \mathrm{ml} \mathrm{RPMI} \mathrm{1640.} \mathrm{After}$ 24 hours, the phagokinetic tracks were visualised by observing the coverslides with a microscope. Several fields were photographed, and areas cleared of gold particles by at least 35 individual cells were measured.

\section{DNA TRANSFECTION}

DNA transfection was performed essentially as described previously. ${ }^{24}$ A full length cDNA encoding human matrilysin was subcloned into the eukaryotic expression vector pcDNA I neo (Invitrogen, San Diego, California, USA). Transfection of CHC-Y1 cells was performed with LipofectAMINE (Gibco, Gaithersberg, Maryland, USA) following the manufacturer's protocol. After a few weeks of G418 selection, individual colonies were picked and expanded for further analysis. Transfectants containing the selection neoplasmid pcDNA I alone were used as controls.

\section{NORTHERN BLOT ANALYSIS}

Northern blot analysis was performed essentially as described previously. ${ }^{12}$ Total RNA was isolated from cells by the acid guanidinium thiocyanate/phenol/chloroform method; $10 \mu \mathrm{g}$ was used for the northern blot analysis. The membrane was hybridised with a matrilysin cDNA probe labelled by the random primer method in $50 \%$ formamide $/ 5 \times$ Denhardt's solution $/ 3 \times$ SSC (where $1 \times$ SSC is $0.15 \mathrm{M}$ $\mathrm{NaCl} / 0.015 \mathrm{M}$ sodium citrate) $/ 100 \mathrm{mg} / \mathrm{ml}$ salmon sperm DNA/ $1 \%$ sodium dodecyl sulphate (SDS) at $42^{\circ} \mathrm{C}$ overnight. After a wash, the membrane was exposed to $x$ ray film at $-70^{\circ} \mathrm{C}$ with an intensifying screen. A $\beta$-actin cDNA probe was used to control the quantity of loading and integrity of total RNA in each lane.

\section{ZYMOGRAPHIC ANALYSIS}

Zymography was performed essentially as described previously. ${ }^{12}$ Tissues were cut up and homogenised in an SDS/polyacrylamide gel electrophoresis sample buffer containing 10\% glycerol, 1\% SDS, and bromophenol blue. Protein content was measured against bovine serum albumin using the Braford method. ${ }^{29}$ Zymography in SDS/polyacrylamide gels containing casein was performed for matrilysin. Equal amounts of protein of homogenised tissues or the culture medium from cells grown for 24 hours in serum-free medium were electrophoresed in a $10 \%$ polyacrylamide gel embedded with $1 \mathrm{mg} / \mathrm{ml}$ casein. After electrophoresis, the gels were washed in $2.5 \%$ Triton 
A
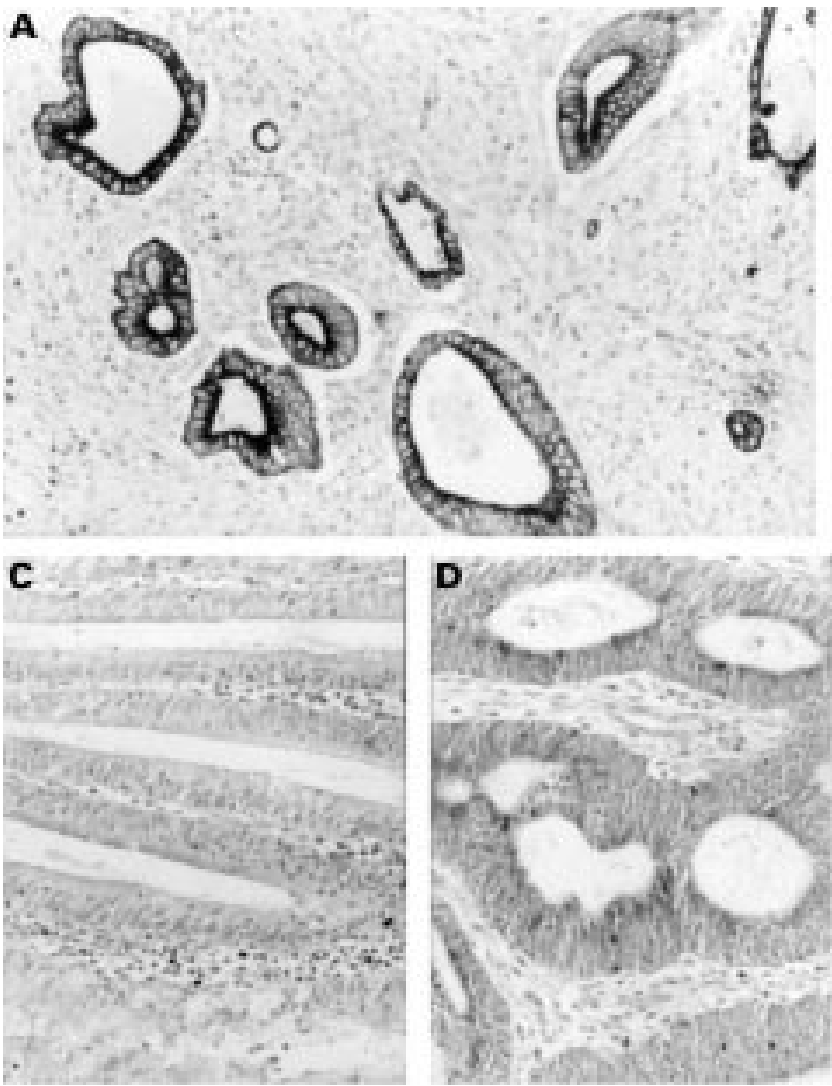
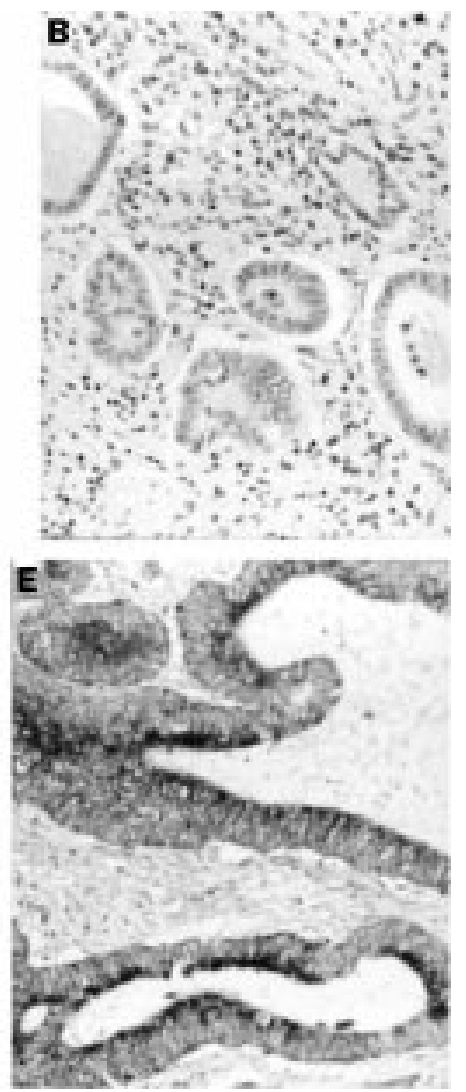

Figure 1 Immunostaining of human colon cancers with anti-matrilysin monoclonal antibody was performed as described in Materials and methods (original magnification $\times 200$ ). (A) A well differentiated adenocarcinoma case of Dukes's type $C$. The monoclonal antibody stained tumour cell cytoplasm and cell membranes, but did not stain the stromal components. (B) Immunostaining with negative control monoclonal antibody of the serial section of $(A)$. Adjacent normal colon epithelium (C) was not stained with anti-matrilysin monoclonal antibody. (D) $A$ well differentiated adenocarcinoma case in Dukes's type D. Metastatic liver nests (E) were stained more strongly than the primary site (D).

$\mathrm{X}-100$ for one hour to remove SDS. The gels were then incubated for 18 hours at $37^{\circ} \mathrm{C}$ in 50 $\mathrm{mM}$ Tris/ $\mathrm{HCl}(\mathrm{pH} 7.5)$, containing $10 \mathrm{mM}$ $\mathrm{CaCl}_{2}$ and $0.02 \% \mathrm{NaN}_{3}$, stained with Coomassie brilliant blue and then destained.

TUMOUR XENOGRAFT MODEL

Cells were harvested from subconfluent cultures by $0.25 \%$ trypsin treatment, and their viability was greater than $95 \%$ as assessed by trypan blue exclusion assays. They were inoculated subcutaneously into the hip region of mice at a concentration of $1 \times 10^{6}$ cells per mouse. The animals were observed daily for tumour growth, and subcutaneous tumours were measured using a caliper every seven days. Tumour volumes were calculated using the formula: tumour volume $=\left(\right.$ length $\times$ width $\left.^{2}\right) / 2$.

Eight mice from each group were killed by cervical dislocation when the first mouse appeared lethargic (day 44), and tumours were examined grossly and histologically. The livers were excised and metastases were counted. To investigate the metastatic potential of the tumours derived from parental cell CHC-Y1, five mice were killed and examined from 57 to 103 days after injection.

STATISTICAL ANALYSIS

The results are presented as means (SE) for each sample. The statistical significance of differences was determined by the $\chi^{2}$ test for the relation between immunohistochemical expression of matrilysin and clinicopathological factors or Dukes's stage and by the MannWhitney $U$ test for the tumour xenograft model. $\mathrm{p}$ values of less than 0.05 were considered to indicate statistical significance.

All data were calculated with the Statview 4.02 statistical software package (Abacus Concepts, Berkeley, California, USA) run on a Macintosh personal computer (Apple Computers, Cupertino, California, USA).

\section{Results}

IMMUNOHISTOCHEMICAL STUDY OF MATRILYSIN EXPRESSION IN RESECTED COLON CANCERS

Seventy eight sections from human colorectal cancers were analysed by immunostaining with an anti-matrilysin monoclonal antibody 1417B2. The antibody stained cytoplasm and membranes of cancer cells (fig 1). The positively stained cells were distributed heterogeneously in the tumour nest and were often located at the invasive front. The stromal com-

Table 1 Relation between immunohistological expression of matrilysin and Dukes's classification

\begin{tabular}{llll}
\hline & $A+B$ & $C+D$ & Total \\
\hline $\begin{array}{lll}\text { Matrilysin positive tumour cells } \\
\leqslant 10 \%\end{array}$ & 21 & 21 & 42 \\
$>10 \%$ & 10 & 26 & 36 \\
Total & 31 & 47 & 78
\end{tabular}

$\mathrm{p}<0.05, \chi^{2}$ test. 
A

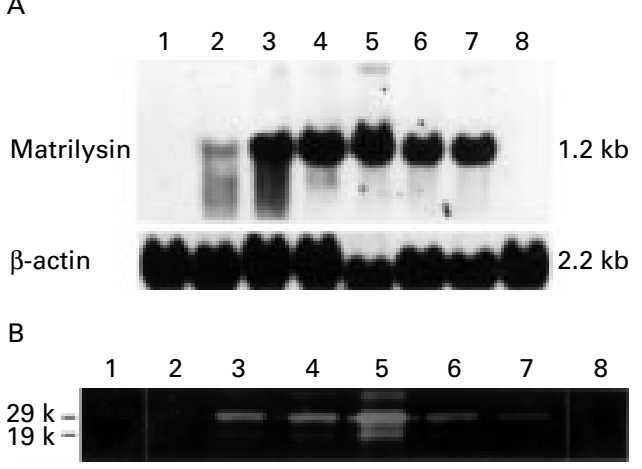

Figure 2 (A) Northern blot analysis and (B) casein zymography of parental cells, sublines of matrilysin transfectants, and mock transfectants were performed as described in Materials and methods. The matrilysin transfectants expressed various levels of matrilysin mRNA (A) and secreted promatrilysin $(29 \mathrm{kDa})$ and activated matrilysin $(19 \mathrm{kDa} ; \mathrm{B})$, but neither was produced by parental cells or mock transfectants: lane 1, CHC-Y1; lane 2, CHC-Mat-1; lane 3, CHC-Mat-2; lane 4, CHC-Mat-3; lane 5, CHC-Mat-4; lane 6, CHC-Mat-5; lane 7, CHC-Mat-6; lane 8, CHC-mock. Clones CHC-Mat-4 (lane 5) and CHC-Mat-6 (lane 7) were used as sublines expressing high and moderate levels of matrilysin respectively.
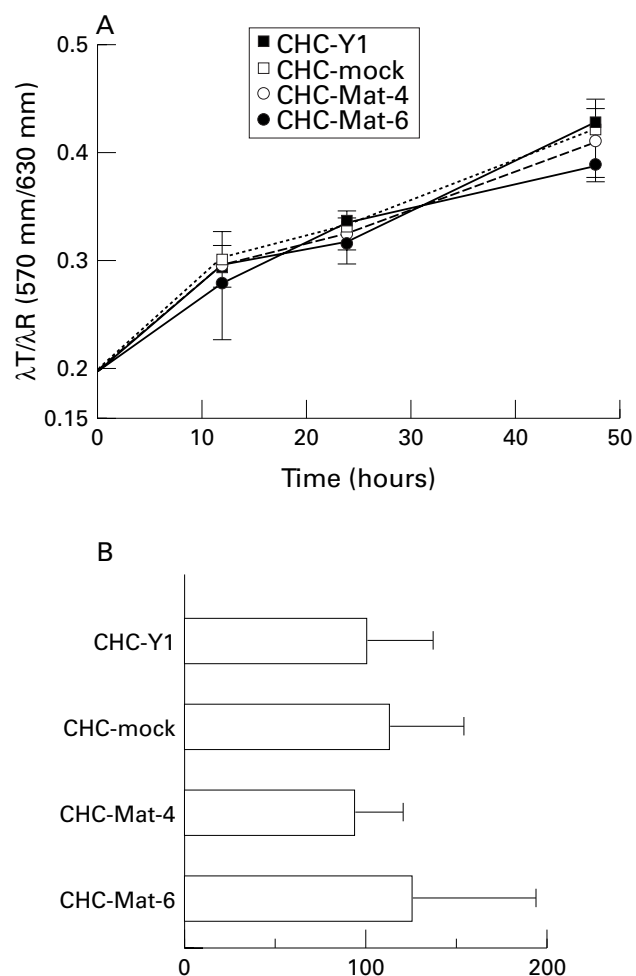

(\%)

Figure 3 (A) 3-(4,5-Dimethylthiazol)-2,5-diphenyltetrazolium bromide assay showed that there was no tetrazolium bromide assay showed that there was no
significant difference in in vitro growth in $C H C-Y 1$, mock transfectants, and matrilysin transfectants. (B) Gold colloid assay showed that in vitro motility of two matrilysin transfected sublines was equivalent to those of parental cell and mock transfectants.

ponents, except for some monocytes, were not stained with the antibody. Benign tissues adjacent to the neoplasm showed no immunoreactivity, indicating that the expression of matrilysin is restricted to malignant cells. In 36 cases $(46 \%)$, over $10 \%$ of cancer cells were stained positively for matrilysin. These cases were sig-

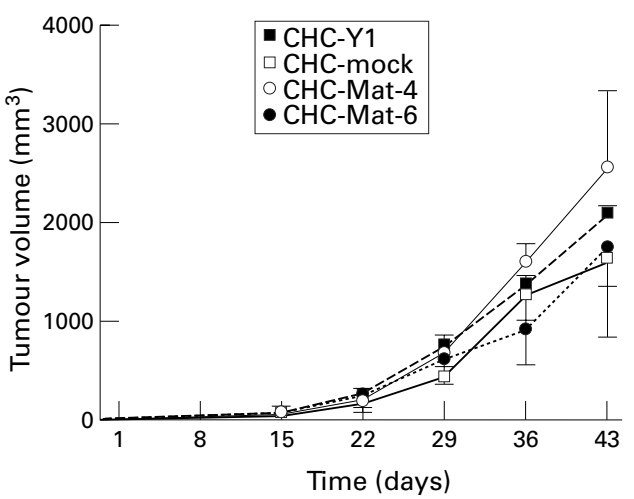

Figure 4 Tumour volumes of transplanted subcutaneous site in SCID mice were measured and calculated every seven days. Growth of tumours derived from two matrilysin transfected sublines was not significantly different from those derived from mock transfectants or parental cell CHC-Y1.

nificantly more common in Dukes's type C+D $(26 / 47,55 \%)$ than in $A+B(10 / 31,32 \%$; $\mathrm{p}<0.05, \chi^{2}$ test; table 1$)$. With regard to each clinicopathological variable, matrilysin only correlated with nodal metastasis $(24 / 42$ in $\mathrm{n}(+)$ $v 12 / 36$ in $\mathrm{n}(-) ; \mathrm{p}<0.05, \chi^{2}$ test $)$.

All five specimens with liver metastasis were stained with the matrilysin monoclonal antibody (fig 1). As regards benign liver tissues, expression of matrilysin was observed in the epithelial cells of bile ducts, but not in hepatocytes. In four liver metastatic lesions that were stained simultaneously with the corresponding primary colon cancers, two metastatic nests were apparently immunostained more strongly than the primary site (fig 1).

\section{TRANSFECTION OF MATRILYSIN CDNA INTO} COLON CANCER CELLS

As the colon cancer cell CHC-Y1 expressed matrilysin mRNA at a level undetectable by northern blot analysis, this cell line was used for the transfection experiments. The matrilysin transfected cells showed various levels of matrilysin mRNA whereas it was not detected in mock transfectants (fig 2A). The enzymic activity of matrilysin was examined by casein zymography. Matrilysin transfectants secreted both zymogen $(29 \mathrm{kDa})$ and the activated form $(19 \mathrm{kDa})$ into the culture medium, but neither form was produced by parental cells or mock transfectants (fig 2B). Clones CHC-Mat-4 (fig 2, lane 5) and CHC-Mat-6 (fig 2, lane 7) were used as sublines expressing high and moderate levels of matrilysin respectively. These transfected clones expressed matrilysin messages and enzymic activity stably during this experiment.

In vitro growth of both CHC-Mat-4 and CHC-Mat-6 did not differ significantly from that of CHC-Y1 or mock transfectants (fig 3A). Also, in vitro motility of both matrilysin transfected sublines was equivalent to that of mock transfectants or parental cells (fig 3B).

TUMORIGENICITY AND INVASIVENESS OF MATRILYSIN TRANSFECTANTS

All sublines of CHC-Mat-4, CHC-Mat-6, mock transfectant, and CHC-Y1 formed tumours at the transplanted subcutaneous site 

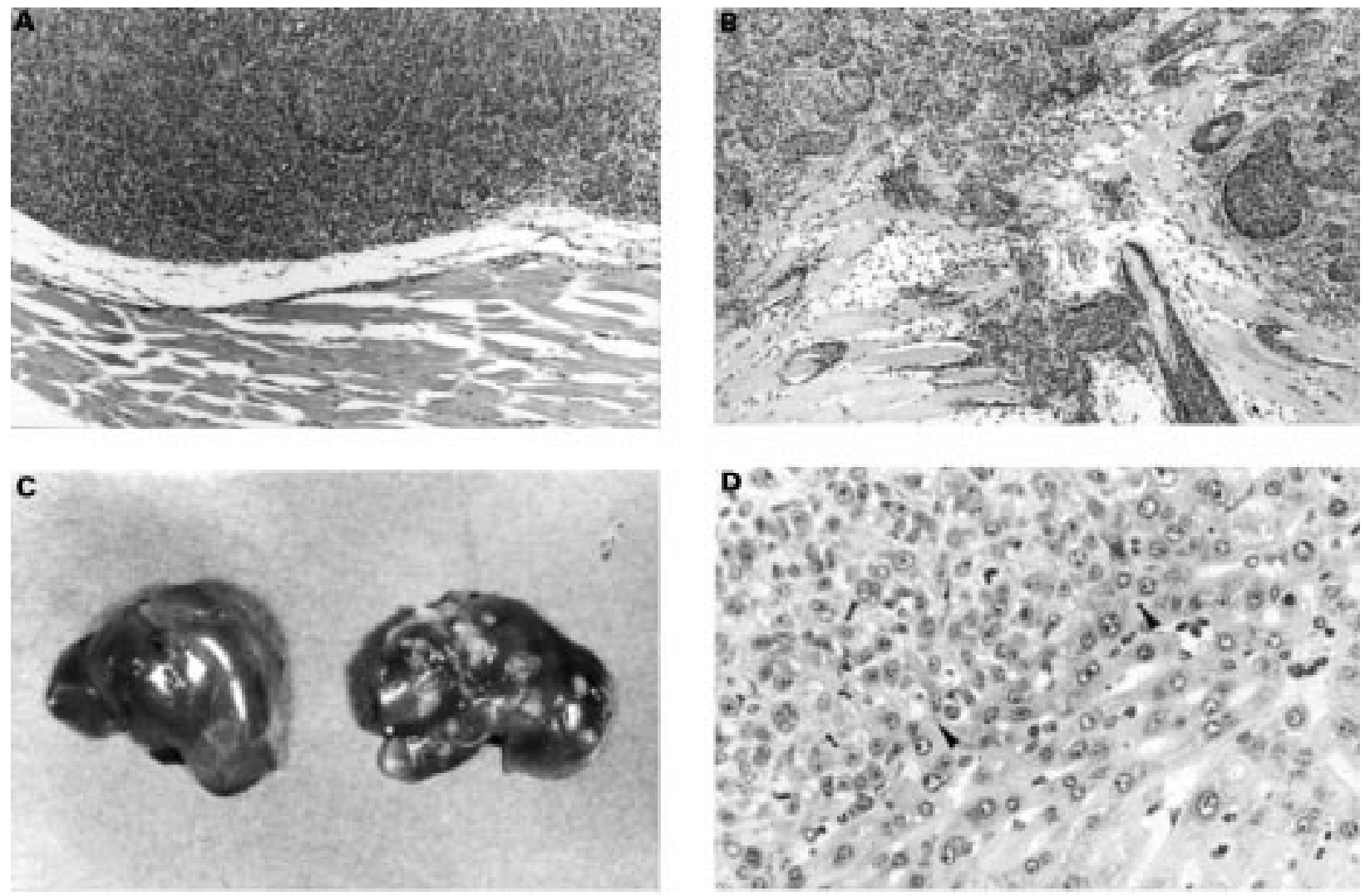

Figure 5 Each subline of matrilysin transfected cancer cells and mock transfectants formed almost the same sized subcutaneous tumour six weeks after injection into SCID mice. (A) Primary subcutaneous tumours of mock transfectants did not invade the muscle tissues (original magnification $\times 100)$. (B) Primary subcutaneous tumours of matrilysin transfectants $C H C-$ Mat-6 invaded the muscle layer (original magnification $\times 100)$. (C) The mice injected with matrilysin transfectants showed multiple liver metastases (right), while those injected with mock transfectants did not (left). (D) Microscopic view of liver metastatic nest (C, right) showing colon cancer cells in left upper side of the field (original magnification $\times 400)$. Arrowheads indicate the border of tumour cells and hepatocytes.

in SCID mice. The size of tumours derived from matrilysin transfectants was not significantly different from that of tumours derived from mock transfectants (fig 4). All tumours derived from matrilysin transfectants had invaded the underlying muscle tissues six weeks after injection, while neither the mock transfectants nor the parental cells showed any invasion (fig 5A,B, table 2). The invasive potential of CHC-Y1 cells per se seems to be very low because three of five SC tumours showed faint invasion of a muscle layer with longer incubation periods (9-15 weeks) after implantation with parental cells into SCID mice. The subcutaneous tumours derived from CHC-Mat-4 and CHC-Mat-6 were shown to express matrilysin $\mathrm{mRNA}$, whereas it remained negative in the tumours derived from parental cells and mock transfectants. The expression

Table 2 Invasion and metastasis after subcutaneous injection of tumour cells into SCID mice

\begin{tabular}{|c|c|c|c|c|c|c|}
\hline \multirow[b]{2}{*}{ Cell line } & \multirow[b]{2}{*}{$\begin{array}{l}\text { Time of } \\
\text { autopsy } \\
\text { (days) }\end{array}$} & \multicolumn{2}{|c|}{ Primary tumour } & \multicolumn{3}{|c|}{ Liver metastasis } \\
\hline & & Incidence & $\begin{array}{l}\text { Invasion of } \\
\text { muscle layer }\end{array}$ & Incidence & $\begin{array}{l}\text { Mean number } \\
\text { of tumour } \\
\text { nodules/ } \\
\text { mouse }\end{array}$ & Range \\
\hline \multirow[t]{2}{*}{ CHC-Y1 } & 44 & $8 / 8$ & $0 / 8$ & $0 / 8$ & 0 & 0 \\
\hline & $57-103$ & $5 / 5$ & $3 / 5$ & $0 / 5$ & 0 & 0 \\
\hline CHC-Mat-4 & 44 & $8 / 8$ & $8 / 8$ & $8 / 8$ & $14.5(1.3)$ & $9-19$ \\
\hline CHC-Mat-6 & 44 & $8 / 8$ & $8 / 8$ & $8 / 8$ & $6.0(0.5)^{\star}$ & $4-8$ \\
\hline CHC-mock & 44 & $8 / 8$ & $0 / 8$ & $0 / 0$ & 0 & 0 \\
\hline
\end{tabular}

^Significantly different from CHC-Mat-4, $\mathrm{p}=0.0007$ (Mann-Whitney U test). levels of MMP-2 mRNA were similar among subcutaneous tumours derived from each subline (data not shown). Both latent and activated forms of matrilysin were secreted in the tumours derived from the matrilysin transfectants. CHC-Mat-4 showed higher matrilysin activity than CHC-Mat-6, reflecting their relative message levels (fig 6A). It is of note that the ratio of active to latent matrilysin was higher in the subcutaneous tumours than in the culture medium of matrilysin transfectants (figs 2B and $6 \mathrm{~A})$.

\section{LIVER METASTASIS SUBSEQUENT TO}

SUBCUTANEOUS INJECTION

In spite of no significant differences in subcutaneous tumour growth, multiple liver metastases were seen in the mice injected with matrilysin transfectants six weeks after injection (fig 5C,D, table 2). No metastatic lesion was observed in mock transfectants or parental cells at all, even though the mice were killed 9 to 15 weeks after implantation. The number of metastatic liver nodules in mice transplanted with the CHC-Mat-4 (mean 14.5, range 9-19) was greater than that with the CHC-Mat-6 (mean 6.0, range 4-8; p $=0.0007$, MannWhitney U test; table 2). The metastatic liver nodules expressed matrilysin, but normal murine liver did not secrete it (fig 6B). This enzyme was effectively activated in the metastatic lesions as well as in primary subcutaneous tumours, whereas matrilysin secreted into 
A

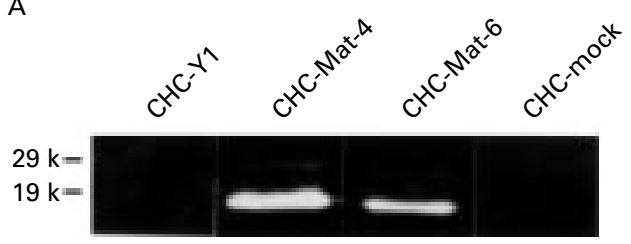

B

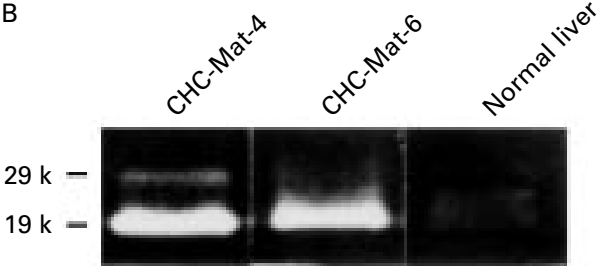

Figure 6 Primary and metastatic tumours of SCID mice were analysed by zymography as described in Materials and methods. (A) Casein zymography showed that primary subcutaneous tumours derived from the two matrilysin transfectants produced matrilysin, the active form (19k) of which was much more abundant than the latent form (29k). (B) Casein zymography of liver showed that activated matrilysin was effectively expressed in metastatic lesions but neither form of matrilysin was detected in normal murine liver.

the culture medium was mainly zymogen (figs $6 \mathrm{~B}$ and $2 \mathrm{~B})$.

\section{Discussion}

Firstly, we have shown that immunohistochemical expression of matrilysin in colon cancer tissue is more common in Dukes's type $\mathrm{C}+\mathrm{D}$ than in type $\mathrm{A}+\mathrm{B}$, as well as in nodal metastasis cases than in negative ones, indicating that it correlates with the presence of some metastases. This result is supported by previous reports in which matrilysin mRNA expression was greater in colorectal cancer than in paired normal colorectal mucosa, and its message level increased with Dukes's type. ${ }^{21-23}$ Metastatic liver tumours, moreover, expressed matrilysin equally to or more strongly than the primary site, supporting a hypothesis that matrilysin plays a crucial role in colon cancer metastasis. In most of the colorectal cancer tissues, matrilysin was not stained homogeneously in the tumour nodules. Moreover, matrilysin staining in cancer cells was quite often observed at the invasive front, suggesting that it may be induced by tumour-host interactions, which are considered to be very important in tumour progression. ${ }^{11} 3031$

We have shown that overexpression of matrilysin made the colon cancer cell CHC-Y1 alter its in vivo invasive potential, in spite of having no significant influence on the character of tumour cell growth or motility. This observation confirms our previous report that matrilysin modulates in vitro invasive potential of colon cancer cells, ${ }^{24}$ and another report on prostate cancer cells in vivo. ${ }^{32}$ We have also obtained evidence that induction of matrilysin enhanced the metastatic potential of colon cancer cells. Furthermore, the ratio of active to latent matrilysin in tumours in vivo increased in contrast with the cells in culture. These results suggest that not only expression but also activation of matrilysin enables these cells to metastasise efficiently. This is supported by the fact that the number of liver metastatic lesions was increased in proportion to matrilysin activity. Activation of MMPs is one of the most critical steps in controlling their enzyme activity and is proposed to be mediated by host-tumour interactions and by several proteinases, such as serine proteinases, stromelysin-1, and MT1-MMP. ${ }^{11} 30313334 \mathrm{Ca}-$ sein zymography is one of the best methods for assessing the enzymic activity of matrilysin, which is difficult to evaluate using antibodies. A knowledge of how the proteolytic activation occurs in vivo is very important in order to understand the metastatic pathway in colorectal cancers.

There are at least two explanations for the enhancement of colon cancer invasion and metastasis by matrilysin overexpression in vivo. One is that it is due to the direct effects of matrilysin, as this proteinase exhibits a wide spectrum of substrate specificity and effectively degrades several components of basement membranes. ${ }^{6-8}$ Another is that it occurs through indirect effects of matrilysin, such as activation of gelatinases $\mathrm{A}$ and $\mathrm{B} .{ }^{34}{ }^{35}$ Our preliminary data showed no apparent differences in gelatinase activity between the tumours, suggesting that the latter explanation is unlikely. However, we cannot rule out other indirect effects of matrilysin, such as an activation of other MMPs or inactivation of serine proteinase inhibitors.

Matrilysin transfected SW480 colon cancer cells were reported to not metastasise after transplantation into nude mice, in spite of their enhanced in vitro invasive potential. ${ }^{36}$ One of the reasons for this inconsistency may be the difference in matrilysin activity in vivo, although there is no available information on SW480 cells. Nevertheless, the discrepancy suggests that overexpression of matrilysin alone may not be sufficient to acquire the full ability to metastasise.

The human colon cancer CHC-Y1 cell was able to invade the muscle layer when subcutaneous tumours were allowed to grow for long periods. This cancer cell, however, does not appear to metastasise readily to the liver in SCID mice, because CHC-Y1 produced liver metastases in only one out of 10 mice, four to seven weeks after intrasplenic inoculation (unpublished data). Matrilysin may modify the character of the cell in mice, in such a way that invasion and then metastasis are made possible. Taking the recent reports that matrilysin increases the tumorigenic potential of neoplastic colon cells into consideration, this proteinase may affect the cell in an as yet unknown manner. ${ }^{8}$ A greater understanding of this molecule is required.

In summary, immunohistological expression of matrilysin correlated with Dukes's classification in colon cancer specimens, and introduction of matrilysin into colon cancer cells markedly upregulated their in vivo invasive and metastatic potential, suggesting that matrilysin may play a critical role in colorectal cancer progression. 
This work was supported by grants-in-aid from the Japanese Ministry of Education, Science, Sports and Culture (to F I, Y H, and $\mathrm{K} \mathrm{I}$ ) and the Japanese Ministry of Health and Welfare (to F I, Y H, and K I). The authors thank Dr David P Carbone, Vanderbilt Cancer Center, for editorial assistance, Fuji Chemical
Industries for the gift of anti-matrilysin monoclonal antibody, and the Japanese Cancer Research Resources Bank for providing a cell.

1 Brikedal-Hansen H, Moore WGI, Bodden MK, et al. Matrix metalloproteinases: a review. Crit Rev Oral Biol Med 1993;4:197-250

2 Stetler-Stevenson WG, Hewitt R, Corcoran M. Matrix metalloproteinases and tumour invasion: from correlation and causality to the clinic. Semin Cancer Biol 1996;7:147-54.

3 Crawford HC, Matrisian LM. Mechanisms controlling the transcription of matrix metalloproteinase genes in normal and neoplastic cells. Enzyme Protein 1996;49:20-37.

4 Baragi VM, Fliszar CJ, Conroy MC, et al. Contribution of the C-terminal domain of metalloproteinases to binding by the inhibitor of metalloproteinases: C-terminal truncated stromelysin and matrilysin exhibit equally compromised binding affinities as compared to full-length stromelysin. $\mathcal{F}$ Biol Chem 1994;269:12692-7.

5 DeClerck YA, Perez N, Shimada H, et al. Inhibition of invasion and metastasis in cells transfected with an inhibitor of metalloproteinases. Cancer Res 1992;52:701-8.

6 Woessner JF Jr, Taplin C. Purification and properties of a small latent matrix metalloproteinase of the rat uterus. $\mathscr{f}$ Biol Chem 1988;263:16918-25.

7 Miyazaki K, Hattori Y, Umenishi F, et al. Purification and characterization of extracellular matrix-degrading metalloproteinase, matrin (Pump-1), secreted from human rectal carcinoma cell line. Cancer Res 1990;50:7758-64.

8 Wilson CL, Matrisian LM. Matrilysin: an epithelial matrix metalloproteinase with potentially novel functions. Int $\mathcal{F}$ Biochem Cell Biol 1996;28:123-36.

9 McDonnell S, Navre M, Coffey R, et al. Expression and localization of the matrix metalloproteinase pump-1 (MMP-7) in human gastric and colon carcinoma. Mol Carcinog 1991;4:527-33.

10 Yoshimoto $\mathrm{M}$, Itoh $\mathrm{F}$, Yamamoto $\mathrm{H}$, et al. Expression of MMP-7 (PUMP-1) mRNA in human colorectal cancers. Int $\mathcal{F}$ Cancer 1993;54:614-18.

11 Yamamoto H, Itoh F, Hinoda Y, et al. Expression of matrilysin mRNA in colorectal adenomas and its induction by truncated fibronectin. Biochem Biophys Res Commun 1994 201:657-64

12 Yamamoto $\mathrm{H}$, Itoh F, Adachi Y, et al. Relation of enhanced secretion of active matrix metalloproteinases with tumour spread in human hepatocellular carcinoma. Gastroenterology 1997;112:1271-7.

13 Levy AT, Cioce V, Sobel ME, et al. Increased expression of the $\mathrm{Mr}$ 72,000 type IV collagenase in human colonic adenocarcinoma. Cancer Res 1991;51:439-44.

14 Murray GI, Duncan ME, O'Neil P, et al. Matrix metalloproteinase-1 is associated with poor prognosis in colon cancer. Nat Med 1996;2:461-2.

15 Pyke C, Ralfkiær E, Tryggvason K, et al. Messenger RNA for two type IV collagenases is located in stromal cells in human colon cancer. Am f Pathol 1993;142:359-65.

16 Porte H, Chastre E, Prevot S, et al. Neoplastic progression of human colorectal cancer is associated with over-expression of the stromelysin-3 and BM-40/SPARC genes. Int 7 Cancer 1995;64:70-5.

17 Okada A, Bellocq J-P, Rouyer N, et al. Membrane-type matrix metalloproteinase (MT-MMP) gene is expressed in stromal cells of human colon, breast, and head and neck carcinomas. Proc Natl Acad Sci USA 1995;92:2730-4.
18 Zeng ZS, Guillem JG. Distinct pattern of matrix metalloproteinase 9 and tissue inhibitor of metalloproteinase 1 mRNA expression in human colorectal cancer and liver mRNA expression in human colorectal

19 Zucker S, Lysik RM, DiMassimo BI, et al. Plasma assay of gelatinase B: tissue inhibitor of metalloproteinase complexes in cancer. Cancer 1995:76:700-8

20 Liabakk N-B, Talbot I, Smith RA, et al. Matrix metalloproteinase 2 (MMP-2) and matrix metalloproteinase 9 (MMP-9) type IV collagenases in colorectal cancer. Cancer Res 1996;56:190-6.

21 Newell KJ, Witty JP, Rodgers WH, et al. Expression and localization of matrix-degrading metalloproteinases during

22 Mori M, Barnard GF, Mimori K, et al. Over-expression of matrix metalloproteinase-7 mRNA in human colon carcinomas. Cancer 1995;75:1516-19.

23 Ishikawa T, Ichikawa Y, Mitsuhashi M, et al. Matrilysin is associated with progression of colorectal tumour. Cancer Lett 1996;107:5-10

24 Yamamoto H, Itoh F, Hinoda Y, et al. Suppression of matrilysin inhibits colon cancer cell invasion in vitro. Int $\mathrm{f}$ Cancer 1995;61:1-5.

25 Itoh F, Yamamoto H, Hinoda Y, et al. Enhanced secretion and activation of matrilysin during malignant conversion of human colorectal epithelium and its relationship with invaive potential of colon cancer cells. Cancer 1996;77:171721.

26 Sato Y, Mukai K, Watanabe S, et al. The AMeX method; a simplified technique of tissue processing and paraffin embedding with improved preservation of antigens for immunostaining. Am f Pathol 1986;125:431-5.

27 Ohuchi E, Azumano I, Yoshida S, et al. A one-step sandwich enzyme immunoassay for human matrix metalloproteinase 7 (matrilysin) using monoclonal antibodies. Clin Chim Acta 1996;244:181-98.

28 Albrecht-Buhler G. The phagokinetic tracks of 3T3 cells. Cell 1971;11:395-404.

29 Bradford MM. A rapid and sensitive method for the quantification of microgram quantities of protein utilizing the principle of protein-dye binding. Anal Biochem 1976;72: $248-54$

30 Borchers AH, Powell MB, Fusenig NE, et al. Paracrine factor and cell-cell contact-mediated induction of protease and c-ets gene expression in malignant keratinocyte/dermal fibroblast cocultures. Exp Cell Res 1994;213:143-7.

31 Nakajima M, Morikawa K, Fabra A, et al. Influence of organ environment on extracellular matrix degradative activity and metastasis of human colon carcinoma cells. $\mathcal{F}$ Natl Cancer Inst 1990;82:1890-8.

32 Powel WP, Knox JD, Navre M, et al. Expression of the metalloproteinase matrilysin in DU-145 cells increases their invasive potential in severe combined immunodeficient mice. Cancer Res 1993;53:417-22.

33 Sato H, Takino T, Okada Y, et al. A matrix metalloproteinase expressed on the surface of invasive tumour cells. Nature 1994;370:61-5.

34 Imai K, Yokohama Y, Nakanishi I, et al. Matrix metalloproteinase 7 (matrilysin) from human rectal carcinoma cells. Activation of the precursor, interaction with other matrix metalloproteinases and enzymatic properties. $\mathcal{F}$ Biol Chem 1995;270:6691-7.

35 Crabbe T, Smith B, O'Connell J, et al. Human progelatinase A can be activated by matrilysin. FEBS Lett 1994;345:1416.

36 Witty JP, McDonnell S, Newell KJ, et al. Modulation of matrilysin levels in colon carcinoma cell lines affects tumourigenicity in vivo. Cancer Res 1994;54:4805-12. 